\title{
Investigating the Impact of Lean Management on Innovation in Vietnamese SMEs
}

\author{
Huong Thu Pham ${ }^{1}$ \\ ${ }^{1}$ Foreign Trade University, Vietnam \\ Correspondence: Huong Thu Pham, Foreign Trade University, Vietnam. \\ Received: August 21, 2017 \\ Accepted: September 7,2017 \\ Online Published: September 19, 2017 \\ doi:10.5539/ibr.v10n11p1 \\ URL: https://doi.org/10.5539/ibr.v10n11p1
}

\begin{abstract}
Internationalization in society and economy has fostered promptly the production volumes and product diversification due to the complexity in customers' design. Lean management has been known as effective and efficient tools in the management of customer value by reducing cost of the resources necessary to achieve the needs of customers. Today inno vation has been considered as driving force of business success in every industry in the context of high competition. The link between lean management and innovation capability has been recently proposed in some literatures, which show that some aspects of lean management may negatively affect and some may positively affect a company's capability to be successful with certain types of innovations. This paper develops a framework to analyze the impact of lean management on innovation capability in Vietnamese small and medium enterprises. Five propositions has been presented and tested in the sample of 122 SMEs engaged in lean management. The findings suggest that due to implementation of lean management the changes of organizational structure and inter-departmental coordination have positive effect and the changes of human resources management and organizational culture have negative effect on the innovation capability.
\end{abstract}

Keywords: lean management, innovation capability, SMEs

\section{Introduction}

\subsection{Introduce the Problem}

Lean management has been currently implemented in Vietnamese SMEs under the support of National Program on "Improving Productivity and Product Quality of Vietnamese Enterprises" since 2010 and Cooperation Program between Vietnam and Japan on improving Vietnamese enterprises' efficiency and quality since 2009. Lean management concentrates on removing any wastes that do not add value to the final product. The enterprises engaged in lean management tend to set up the rules and standardizations throughout entire process to prevent any forms of non value-adding activities.

Today innovation has been considered as the driving force of business success, especially for the SMEs to strongly compete in both domestic and international market. The enterprises not only stress on the group of innovative engineers but also create the flexible environment in which all employees are able to develop and explore creativity aiming at adding values to the enterprises. Setting up the encouraging environment for creativity and innovation needs resources and does not bring about the added value at the present. The enterprises normally do not know whether the innovation could bring about the added values even in future.

By fundamental concepts and objectives, some aspects of the lean management are likely restrict innovation and it makes confusion in the group of innovative employees that applying lean management means all activities that does not add value to the current customers should be discouraged at all. A question is that how can enterprises impulse innovation while maintaining a good level of lean practices.

In this paper, the framework to explore the impacts of lean management on an SMEs' innovation capability are built up and a practical investigation based on that is carried out with the sample of 122 Vietnamese SMEs. Both negative and positive effects to innovation capability of enterprises engaged in lean are approached. The interesting link between lean management and innovation presented is background for proposing the suggestions to achieve balance between successful lean practices and improving innovation capability. 


\subsection{Literature Review}

\subsubsection{Lean Management}

The philosophy of lean was originated by Toyota in 1950s and first defined in the book published in 1990, The Machine that Changed the World, based on the Massachusetts Institute of Technology's study on the automobile. The techniques of eliminating muda (waste) and coordinating the flow of parts within the supply chain in the famous Toyota Production System (TPS) were initiated by Taiichi Ohno, a production genius of Toyota Motor Corporation. Two backbones of the TPS include just-in-time system (JIT) in which "parts would only be produced at each previous step to supply the immediate demand of the next step" and Jidoka system in which the problems are identified and traced right in the process and no detective parts would be transferred to the next step (James P. Womack et al., 1990, p.49-69).

The main objective of lean philosophy is increasing the efficiency by improving the flow of the system, applying only value adding time and steps into the organization and eliminating all waste. James P.Womack and Daniel T. Jones (1996) brought the concept of "lean thinking" that is eliminating any things not necessary to production by concentrating on exactly what customers need. There five principles of lean thinking including value, value stream, flow, pull and perfection. (James P.Womack \& Daniel T. Jones, 1996, p.306-311)

- Value is defined as "capability provided to customer at the right time at an appropriate price, as defined in each case by the customer".

- Value stream is defined as the set of all the "specific activities required to design, order, and provide a specific product, from the concept to launch, order to delivery, and raw materials into the hands of the customer". There are three types of activities in the value stream including activities that unambiguously create value, activities that create no value but seem to be unavoidable, activities that create no value and are immediately avoidable.

- Flow is defined as the "progressive achievement of tasks along the value stream so that a production proceeds from design to launch, order to delivery and raw material into the hands of customer with no stoppages, scrap or backflows".

- Pull is defined as the "system of cascading production and delivery instructions from downstream to upstream in which nothing is produced by the upstream supplier until the downstream customer signals a need".

- Perfection is defined as the "complete elimination of muda so that all activities along a value stream create value".

Aiming to the objective of lean philosophy, there might be changes in organizational structure, intercommunication, experience and skills of employees, product designing process and culture in SMEs engaged in lean.

In most of publication, it is claimed that creating smooth flow and value stream orients the organizations to be more flexible. A flat and flexible organizational structure allows managers to be closer to the shop floor and shortens feedback time, which results in improving information flow, clarity and speeds up decision making (Drew, McCallum \& Roggenhofer, 2004, p.52). The longer an organization has been engaged in implementing or using lean, the more flexible structure it had (Faron A., 2012, p.110). The fewer layer in organizational hierarchy to enable quick response and a high level of horizontal integration to increase knowledge transfer (Nahm et al., 2003, p.282). Lean management will lead to a simplification of tasks and these tasks are performed in a reduced space (Paez, O., et al., 2004, p.293). In order to eliminate non value adding activities and create flow, all employees need to think of simplifying their work by standardizing their work, so that a given task will take the same amount of time every time and also will be done correctly on the first attempt (Womack \& Jones, 1996, p.10). Thus, lean management might goes with the lower level of specialization, higher level of horizontal and fewer layers in organizational hierarchy.

Smoothing the flow of information is considered as a condition to unstop the value stream and lean production development proposes a "seamless information flow" (McManus, 2004). Breaking inter-departmental barriers within the organization and let information flow both horizontally and vertically to smooth the flow of information has seen as success factor in implementation of lean management (R.P. Mishra \& A. Chakraborty, 2014, p.165-167). Multi-functional teams in which the members come from different department of SMEs have been broadly deployed and play important roles in implementing lean (Sanchez, A.M. \&Perez, M.P., 2001, p.1433-1451). A fundamental strategy in lean is the bottom-up strategy in which employees are involved in continuous improvement process in discovering the sources of waste so as to discard them (Hann et al., 2012). 
Lean management might change the inter-departmental coordination in SMEs, in which information of customer's demand and characteristics is shared and all departments are involved in building up the strategy.

Parker (2003, p.631) found that although the work speed improved in lean practice the stress due to lean job increased, the autonomy and skill utilization of employees decreased. Standardization leads to decreased levels of commitment and less motivation as well as less informal communications. The multi-functionality and high productivity requirements on employees lead to the loss of specialized expertise (H.Chen \& R.Taylor, 2009, p.830). Lean management might change human resource management that the employees face with more stress and have less motivation, autonomy, skill utilization and less informal communication.

As for the purpose of increasing the efficiency by improving the flow of the system, applying only value adding time and steps into the organization and eliminating all waste in lean management, design for manufacturability and standardization are two main practices in lean design. Design for manufacturability is expected to increase the efficiency and asset utilization by simplifying the design, minimizing the number of product parts and standardizing parts and process. Standardization defines the way product design is to be completed every time with standard procedures, standard materials and standard parts, match new design with existing components and manufacturing methods. (H.Chen \& R.Taylor, 2009, p.829-830). Since the lean thinking emphasis on value defined by customers thus product design should base on the customers' requirements and all non-value adding activities in designing should be eliminated. Lean management might change the process of production design, in which process, material, product parts are standardized, number of product parts is minimized, the product design are compatible with existing manufacturing procedures and processes, all non-value adding activities are eliminated and customers'requirements are followed in designing new product.

Concentrating on waste identification and elimination as well as organizing all activities around value streams make culture in lean organization differ from the traditionally organized ones (W., Urban, 2015, p.135). Lean concepts promote the reduction of any slack or underutilized design resources, any risks or potential failures that can result in necessary corrections, any variability to achieve product quality at relatively low costs (H.Chen \& R.Taylor, 2009, p.829). Lean management might change the culture of SMEs, in which all attention of both managers and employees are cutting non-necessary resources, minimizing risk and reducing variability in keeping required quality.

\subsubsection{Innovation}

Inno vation was referred to be the single most important factor to boost the economy. According to Albury (2005, p.52), "successful innovation is the creation and implementation of new processes, products, services and methods of delivery which result in significant improvements in outcomes, efficiency, effectiveness or quality". H.Chen and R.Taylor (2009, p.827) explains "innovation as implementation, institutionalization and commercialization of new and creative ideas".

Various form of innovation has been proposed in literature such as product or process innovation, administrative or technological innovation, radical or incremental innovation, etc. Product innovation is defined as new outputs that are introduced for the benefits of customers meanwhile process innovation is considered as new tools, devices, procedures as well as knowledge in throughput technology that mediate between inputs and out puts (Utterback and Abernathy, 1975, p.641-647). Henderson and Clark (1990, p.12-15) use distinction between component and system knowledge to differentiate four categories of innovation including incremental, modular, architectural and radical innovation. Incremental innovation makes improvements on existing design through improvements in the components. Incremental innovation is the most popular innovation in which gradual improvements in knowledge and materials lead to most products and services being enhanced overtime. Modular innovation uses the architecture and configuration associated with the existing system but employs new components with different design concept. Architectural innovation use the new architecture and configuration of the system as new linkages are instituted meanwhile the components and associated design concepts remain unchanged. Radical innovation is on the top of innovation which "establishes a new dominant design, and hence a new set of core design concepts embodied in components that are linked together in a new architecture". Greve, (2007, p.947) presents two forms of innovation, "incremental innovations, as innovations which advance existing technology, and radical innovations, as innovations which develop new technology".

Studying critical factors affect to innovation capability, G. Chryssochoidis (2003) summarizes the factors affecting product innovations in literature in which linkages between organizational demographic characteristics, organizational structure, commitments of managers and employees, environmental conditions of organization, process of strategy formation and product innovation are presented. Marisa Smith and colleagues (2008, p. 659-660) identifies 9 key factors influence organization ability to manage innovation including technology, 
innovation process, corporate strategy, organizational structure, organizational culture, employees, resources, knowledge management, management style and leadership. Haryani S. \& Gupta V.B. (2016, p.1215-1216) figure out five factors affecting to innovation capability of Indian software firms including technological orientation, inter-departmental coordination, competitors orientation, customer orientation and innovative strategies.

\subsubsection{Lean Management and Innovation}

Relationship between lean management and innovation has been investigated in some researches with the purposes of proposing suggestions to balance between lean management and innovation, two driving forces for today's business success.

Based on observation of Toyota Production System, Mehri (2006, p. 21-42) reveals that due to waste minimization and standardization, lean design have a negative effect on workers' potential for creativity and innovation. Adding to Mehri (2006), H.Chen \& R. Taylor (2009, p829-830) study impact of lean management on innovation capability in term of lean culture, lean design, lean supply chain and human resource management. It is argued that there are negative relationships between those dimensions of lean management and innovation capability. The authors suggest that in order to balance between lean management and innovation, the organizations might choose one of these strategies based on its characteristics and products: outsourcing innovation, establishing an independent innovation center, lean innovation system, innovative product development process.

In evaluating the relationship between lean manufacturing dimensions and radical product innovation in Jordanian pharmaceutical sector, Rima Al Hasan and Zu'bi M.F. Al-Zu'bi (2014, p. 230-258) investigate the impact of 4 factors including continuous improvement, waste minimization, lean job characteristics, employee involvement on radical innovation and find that there is negative relationship between lean job characteristics, employees' involvement and radical innovation.

\subsection{Conceptual Framework}

Since the knowledge background about innovation of Vietnamese SMEs is still limited, this study simply categorizes the innovation in two types, incremental innovation and radical innovation. The incremental innovation refers to the improvement of product or process with the existing design and system. Radical innovation is understood that there should be the new technology or the new market developed. By linking the changes in organization due to lean management and the critical factors affect to innovation, in the next section we develop a framework that conceptualizes the impact of lean management on organization's innovation.

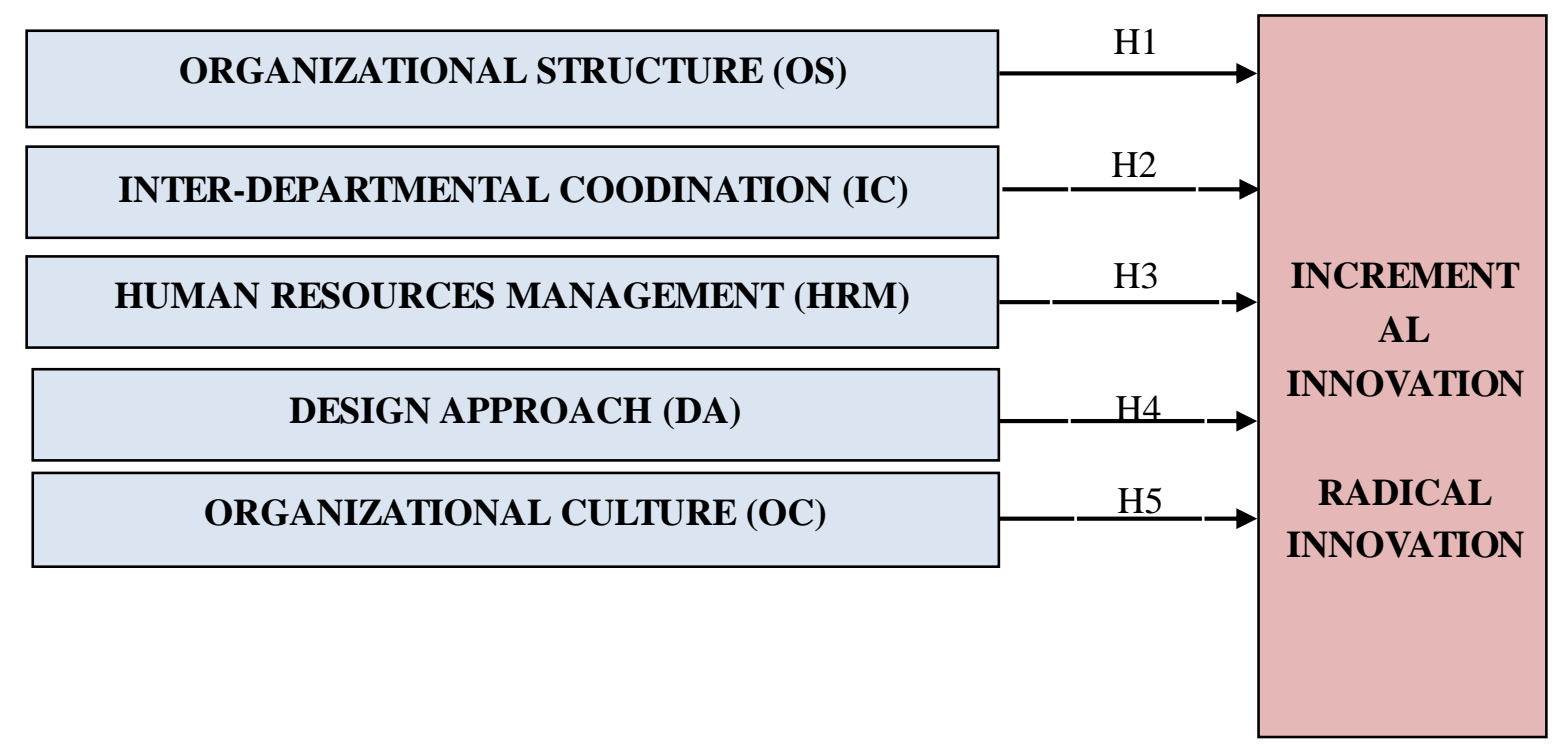

Figure 1. Conceptual Model

As mentioned above, adopting lean philosophy might lead to changes in organizational structure, inter-departmental coordination, human resources management, new product designing process and culture in SMEs engaged in lean. It is presented in previous literature that those might affect to innovation of the organization. Therefore, this study proposes 5 hypotheses on the relationship between lean management and innovation as follows: 
H1a. After implementing lean, the changes in organizational structure will result in higher level of incremental innovation.

H1b. After implementing lean, the changes in organizational structure will result in higher level of radical innovation.

Drew, McCallum \& Roggenhofer (2004, p.52), Faron A. (2012, p.110), Nahm and colleagues (2003, p.282), Paez, O., and colleagues (2004, p.293), Paez, O., and colleagues (2004, p.293), Womack \& Jones (1996, p.10) figure out the impact of lean management on the organizational structrure. G. Chryssochoidis (2003) and Haryani S. \& Gupta V.B. (2016, p.1215-1216) identify the effect of organizational structure to the innovation including incremental and radical innovation.

H2a. After implementing lean, the changes in inter-departmental coordination will results in higher level of incremental innovation.

H2b. After implementing lean, the changes in inter-departmental coordination will results in higher level of radical innovation.

Sanchez, A.M. \&Perez, M.P. (2001, p.1433-1451), McManus (2004), Hann \& colleagues (2012), R.P. Mishra \& A. Chakraborty (2014, p.165-167) argue that lean management might change the inter-departmental coordination in SMEs. Haryani S. \& Gupta V.B. (2016, p.1215-1216) prove that the higher level of inter-departmental coordination will result in higher level of innovation.

H3a. After implementing lean, the changes in human resource management will result in lower level of incremental innovation.

H3b. After implementing lean, the changes in human resource management will result in lower level of radical innovation.

Parker (2003, p.631) and H.Chen \& R.Taylor (2009, p.830) present that lean management might lead to more stress, less motivation, autonomy and skill utilization and less informal communication of employees. Those results might affect to the innovation capability of the organizations.

H4a. After implementing lean, the lean approach of new product design will result in lower level of incremental innovation.

H4b. After implementing lean, the lean approach of new product design will result in lower level of radical innovation.

Marisa Smith and colleagues (2008, p. 659-660), H.Chen \& R.Taylor (2009, p829-830) and Mehri (2006, p. 21-42) argue that lean management changes the approach of new product design and this will result in lower level of innovation.

H5a. After implementing lean, the lean organizational culture will result in lower level of incremental innovation.

H5b. After implementing lean, the lean organizational culture will result in lower level of radical innovation.

One of the most critical factors affecting on the implementation of lean management is organizational culture. The organization should change the organizational culture to make it appropriate to the lean philosophy (W., Urban, 2015, p.135), (H.Chen \& R.Taylor, 2009, p.829). G. Chryssochoidis (2003), Marisa Smith and colleagues (2008, p. 659-660) identify the organizational culture is a critical factor effecting to the organizations' innovation.

\section{Methodology}

\subsection{Compiling the Questionnaire}

To carry out innovation measurements in Vietnamese SMEs as well as the impact of lean management on the organizations, this study develop a data collection questionnaire based on the above literature review and conceptual model. Questionnaire is presented in Vietnamese and composed of 3 main parts including lean implementation, innovation capability and impact of lean implementation on innovation. Based on the analysis of the changes in organizations due to implementation of lean, 19 sub-factors, specifying of 5 factors, are proposed to investigate the affect of lean management to Vietnamese SMEs' innovation. The incremental innovation is measured by assessment on improvement of products and/or process meanwhile radical innovation is measured by assessment on new technology and/or new market developed.

In-depth interview with pilot group of managers was conducted in order to make sure that the managers might 
understand the content of questionnaires. The terms related to innovation and lean management was edited in Vietnamese to make it easy for SMEs managers understand the content.

Likert 5 points scales, which are strongly disagree, disagree, neutral, agree and strongly agree, are given to measure SMEs' use lean tools, innovation awareness and culture, changes in SMEs after implementing lean management, as well as level of incremental and radical innovation.

\subsection{Sampling Selection}

In order to investigating the impacts of lean management on Vietnamese SMEs' innovation, this research aimed at 122 companies those joined in the Keieijuku program organized by Vietnam Japan Human Resource Development Institute (VJCC) and funded by JICA from January to July 2017. The reason is that as a main part of Vietnamese SMEs involved in lean management those companies almost get familiar with lean concepts, have at least 3 years of engaging in lean and many of them has been supported in the National Program on "Improving Productivity and Product Quality of Vietnamese Enterprises" and Cooperation Program between Vietnam and Japan on improving Vietnamese enterprises' efficiency and quality since 2009.

The questionnaire was completed by the company executive managers responsible for the whole companies. 250 questionnaires were sent out directly to SMEs, 122 responses were received.

\section{Findings}

\subsection{Reliability}

Cronbach's alpha of all measures except INCREMENTAL are greater than 0.7 which is close to one and Corrected Item-Total Correlation is greater than 0.3, which means that all measurements except INCREMENTAL are reliable (Field, 2011).

Table 1. Item-Total Statistics

\begin{tabular}{|c|c|c|c|c|}
\hline & $\begin{array}{c}\text { Scale Mean if Item } \\
\text { Deleted }\end{array}$ & $\begin{array}{c}\text { Scale Variance if } \\
\text { Item Deleted }\end{array}$ & $\begin{array}{c}\text { Corrected } \\
\text { Item-Total } \\
\text { Correlation }\end{array}$ & $\begin{array}{c}\text { Cronbach's } \\
\text { Alpha if Item } \\
\text { Deleted } \\
\end{array}$ \\
\hline \multicolumn{5}{|c|}{ Cronbach's Alpha $=0.883$ for "Organizational Structure" - OS } \\
\hline OS1 & 7.43 & 1.785 & .763 & .857 \\
\hline OS2 & 7.24 & 2.133 & .817 & .806 \\
\hline OS3 & 7.28 & 2.087 & .763 & .844 \\
\hline \multicolumn{5}{|c|}{ Cronbach's Alpha $=0.769$ for "Inter-departmental Coodination" $-I C$} \\
\hline IC1 & 7.80 & 2.230 & .434 & .857 \\
\hline IC2 & 7.90 & 1.280 & .784 & .459 \\
\hline IC3 & 7.84 & 2.066 & 661 & .650 \\
\hline \multicolumn{5}{|c|}{ Cronbach's Alpha =0.713 for “Human Resource Management" - HRM } \\
\hline HRM1 & 6.57 & 1.585 & 0.696 & 0.42 \\
\hline HRM2 & 6.53 & 1.507 & 0.53 & 0.645 \\
\hline HRM3 & 6.61 & 2.156 & 0.408 & 0.759 \\
\hline \multicolumn{5}{|c|}{ Cronbach's Alpha $=0.853$ for "Design Approach" - DA } \\
\hline DA1 & 15.05 & 7.981 & .656 & .825 \\
\hline DA2 & 15.29 & 7.727 & .717 & .811 \\
\hline DA3 & 15.15 & 6.606 & .786 & .788 \\
\hline DA4 & 14.93 & 8.152 & .712 & .817 \\
\hline DA5 & 15.46 & 7.589 & .525 & .868 \\
\hline \multicolumn{5}{|c|}{ Cronbach's Alpha $=0.744$ for "Organizational Culture" - OC } \\
\hline $\mathrm{OC} 1$ & 7.80 & .887 & 611 & .628 \\
\hline $\mathrm{OC} 2$ & 7.55 & 1.175 & 0750 & .515 \\
\hline OC3 & 7.52 & 1.244 & .426 & .820 \\
\hline \multicolumn{5}{|c|}{ Cronbach's Alpha = 0.297 for "Incremental Innovation" - INCREMENTAL } \\
\hline INCREMENTAL 1 & 3.97 & .379 & .178 & \\
\hline INCREMENTAL 2 & 3.49 & .566 & .178 & \\
\hline \multicolumn{5}{|c|}{ Cronbach's Alpha $=0.985$ for "Radical Innovation" - RADICAL } \\
\hline RADICAL 1 & 3.81 & 0.551 & 0.971 & . \\
\hline RADICAL 2 & 3.84 & 0.529 & 0.971 & . \\
\hline
\end{tabular}

In order to examine the study's hypotheses, multiple regression analysis is conducted. Since measurements of incremental innovation are not reliable so that the regression analysis related to INCREMENTAL would not be carried out. 
Table 2. Model Summary

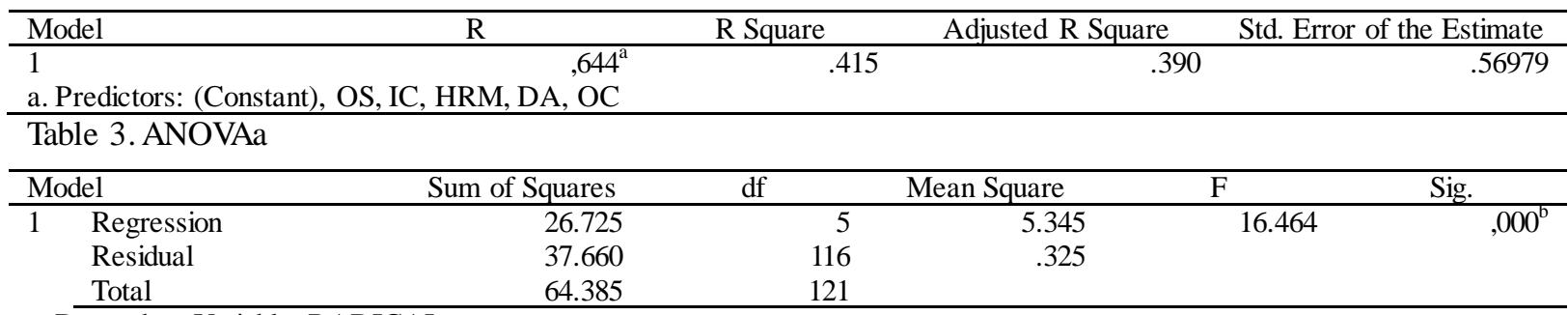

a. Dependent Variable: RADICAL

b. Predictors: (Constant), OS, IC, HRM, DA, OC

The coefficient of the determination ( $\mathrm{R}$ square) in radical innovation testing is equal to 0.415 which means the $41.5 \%$ of variance of the change in radical innovation can be explained by lean affected factors. In the ANOVA analysis, $\mathrm{F}=16.464$ and $\mathrm{Sig} .=0.000$ presents that all independent variables in the regression model have the effect to the dependent variable. This gives it to the appropriation of the research model.

Table 4. Coefficientsa

\begin{tabular}{|c|c|c|c|c|c|c|}
\hline \multirow{2}{*}{\multicolumn{2}{|c|}{ Model }} & \multicolumn{5}{|c|}{$\begin{array}{l}\text { Standardized } \\
\text { Coefficients }\end{array}$} \\
\hline & & $\mathrm{B}$ & Std. Error & Beta & $\mathrm{t}$ & Sig. \\
\hline & (Constant) & 2.915 & .468 & & 6.226 & .000 \\
\hline & OS & .528 & .126 & .448 & 4.204 & .000 \\
\hline & IC & .645 & .146 & .437 & 4.426 & .000 \\
\hline & HRM & -.589 & .127 & -.555 & -4.637 & .000 \\
\hline & DA & .234 & .118 & .217 & 1.976 & .051 \\
\hline & $\mathrm{OC}$ & -.513 & .102 & -.454 & -5.051 & .000 \\
\hline
\end{tabular}

H1b. After implementing lean, the changes in organizational structure will result in higher level of radical innovation.

As for the organizational structure, the value of t-test is significant at $95 \%$ confidence level $(0.000<0.05)$ which means that there is evidence to conclude that the changes of organizational structure due to lean management results in the higher level of radical innovation. The positive beta value (.528) means that the radical innovation increases by $52.8 \%$ as the organizational structure flexibility increases (positive relationship).

H2b. After implementing lean, the change in inter-departmental coordination will results in higher level of radical innovation.

The change in inter-departmental coordination got significant result in relationship with radical innovation, the value of t-test is significant at $95 \%$ confidence level $(0.000<0.05)$. The beta value is 0.645 which means that there is significant positive relationship between inter-departmental coordination and radical innovation in Vietnamese SMEs. The radical innovation rises by $64.5 \%$ as the inter-departmental coordination goes up.

H3b. After implementing lean, the changes in human resource management will result in lower level of radical innovation.

Furthermore, for the human resource management, the t-test value is also significant at $95 \%$ confidence level $(0.000<0.05)$, with negative beta co-efficient $(-0.589)$, which mean that there is evidence to conclude that there is negative relationship between the radical innovation and human resource management, when the employees face with more stress and have less motivation, autonomy, skill utilization and less informal communication due to lean, the radical innovation might be restricted.

H4b. After implementing lean, the lean approach of new product design will result in lower level of radical innovation.

On the other hand, for lean approach of new product design, the value of the t-test is not significant at $95 \%$ confidence level $(0.051>0.05)$, which means that the variance in radical innovation is not predicted by the lean approach of new product design. In other word, either with transforming to lean design approach or not, radical innovation might not be affected.

\section{H5b. After implementing lean, the lean organizational culture will result in lower level of radical innovation.}

Finally, for the organizational culture, the t-test value is significant at $95 \%$ confidence level, which means that there is enough evidence to conclude that there is a relationship between lean organizational culture and radical innovation. The beta co-efficient value is 0.513 , which means that there is negative relationship and the radical 
innovation might reduce by $51.3 \%$ when the enterprises are engaged deeper in to lean.

\section{Discussion and Conclusion}

Regarding to our study aim, it was confirmed that the framework to explore the impacts of lean management on Vietnamese SMEs' innovation capability is appropriate. The practical investigation of 122 Vietnamese SMEs presents that the more SMEs engaging in lean, the more flexible oganizational structure and the higher inter-departemental coodination they are, which result in the higher level of radical innovation. However, when transform deeper into lean, the lean job and lean culture make the negative effect to the radical innovation.

The results show that lean management goes with the lower level of specialization, higher level of horizontal and fewer layers in organizational hierarchy. The flexible organizational structure due to engaging in lean makes it possible to have more radical innovation. This reflects the previous studies including G. Chryssochoidis (2003) and Haryani S. \& Gupta V.B. (2016).

Again the study proves the argument of Sanchez, A.M. \&Perez, M.P. (2001), McManus (2004), Hann \& colleagues (2012), R.P. Mishra \& A. Chakraborty (2014) about the impact of lean management on the inter-departmental coordination in SMEs. The investigation shows the same result to the research of Haryani S. \& Gupta V.B. (2016) that the higher level of inter-departmental coordination will result in higher level of innovation.

Similar to H.Chen \& R.Taylor (2009), the study figures out the negative relationship between human resource management, organizational structure and inno vation capability. Transforming into lean, the employees get more stress, less motivation, autonomy and skill utilization and less informal communication, thus to lower level of the innovation capability of the organizations. It got the same result as for the lean culture. Lean management might change the culture of SMEs, in which all attention of both managers and employees are cutting non-necessary resources, minimizing risk and reducing variability in keeping required quality. This leads to the negative effect to radical innovation of SMEs.

The relationship between the lean approach of new product design and radical inno vation is not significant in the study. It might be the reason that the innovation has been currently emphasized in Vietnamese business community and SMEs invested more in the research and development. Therefore, the lean approach of new product design might not have significant effect to the radical innovation.

The study has linked the changes in organization due to lean management and the critical factors affect to innovation. The interesting link between lean management and innovation is background for proposing the suggestions to achieve balance between successful lean practices and improving innovation capability. The job characteristics such as employees' stress, motivation, autonomy and skill utilization as well as informal communication should be considered significantly when the SMEs get more in lean management.

The limitation of the study is that the results of factor analysis does not give the converge values and the measurements of incremental innovation are not reliable enough. Although the sample size of 122 SMEs might not be large enough to have better result of factor analysis, the framework has been built up based on the results of previous empirical researches and it is supposed that 17 items produce 5 factors investigated above.

\section{References}

Albury, D. (2005). Fostering Innovation in Public Services. Public Money \& Management, 25(1), 51-56.

Chen, H., \& Taylor, R. (2009). Exploring the Impact of Lean Management on Innovation Capability. Proceedings PICMET, August 2-6, Portland, Oregon: University of Minnesota, Duluth, MN-USA. https://doi.org/10.1109/PICMET.2009.5262042

Chryssochoidis, G. (2003). Factors affecting product innovations: a literature review. Journal of Agricultural Economics Review, 04(1), 47-62.

Drew, J., McCallum, B., \& Roggenhofer, S. (2004). Journey to lean. Making organizational change stick. Palgrave MacMillan, New York. https://doi.org/10.1057/9781403948410

Faron, A. (2011). Organizational structures in companies engaged in implementing lean management. M.Fertsch (Ed.), Production systems - selected issues - Theory and Practice, Publishing House of Poznan Uni versity of Technology, Poznan, 163-176.

Field, A. (2011). Discovering Statistics Using SPSS. London SAGE Publication Ltd.

Greve, H. R. (2007). Exploration and exploitation in product innovation. Industrial and Corporate Change, 945-975. https://doi.org/10.1093/icc/dtm013 
Haan, D., Naus, N., \& Overboom, M. (2012). Creative tension in a lean work environment: Implications for logistics firms and workers. International Journal of Production Economics, 13(7), 157-164. https://doi.org/10.1016/j.jpe.2011.11.005

Haryani, S., \& Gupta, V. B. (2016). Factors affecting innovation capability of Indian software firms (with special reference to indore city). International Research Journal of Engineering and Technology, 03(12), 1213-1219.

Henderson, R. M., \& Clark, K. B. (1990). Architectural innovation: the reconfiguration of existing product technologies and the failure of established firms. Administrative Science Quarterly, 35, March 1990, 9-30. https://doi.org/10.2307/2393549

Marisa, S., Marco, B., Peter, B., \& Rober, V. D. M. (2008). Factors influencing an organizations ability to manage innovation: a structured literature review and conceptual model. International Journal of Innovation Management, 12(4), 655-676. https://doi.org/10.1142/S1363919608002138

McManus, H. L. (2004). Product Development Value Stream Analysis and Mapping Manual (PDVSM) - Beta Draft. Cambridge, MA: Lean Aerospace Initiatives.

Mehri, D. (2006). The darker side of lean: an insider's perspective on the realities of the Toyota Production System. Academy of Management Perspectives, 20(2), 21-42. https://doi.org/10.5465/AMP.2006.20591003

Mishra, R. P., \& Chakraborty, A. (2014). Strenghts, weakness, opportunities and threats analysis of lean implementation framework. International Journal of Lean Enterprise Research, 1(2). https://doi.org/10.1504/IJLER.2014.066833

Nahm, A. Y., Vonderembse, M. A., \& Koufterosc, X. A. (2003). The impact of organizational structure on time-based manufacturing and plant performance. Journal of Operations Management, 281-306. https://doi.org/10.1016/S0272-6963(02)00107-9

Paez, O., J., D., A., G., S., T., Karwo wski, W., \& Zurada, J. (2004). The lean manufacturing enterprise: An emerging sociotechnological system integration. Human Factors and Ergonomics in Manufacturing \& Service Industries, 14(3), 285-306. https://doi.org/10.1002/hfm.10067

Parker, S. (2003). Longitudinal effects of lean production on employee outcomes and the mediating role of work characteristics. Journal of Applied Psychology, 88(4), 620-634. https://doi.org/10.1037/0021-9010.88.4.620

Rima, A. H., Zu'bi, M. F., \& Al-Zu'bi (2014). Evaluating the relationship between lean manufacturing dimensions and radical innovation in the Jordanian pharmaceutical. European Scientific Journal, Oct 2014, 10(28).

Sanchez, A. M., \& Perez, M. P. (2001). Lean indicators and manufacturing strategies. International Journal of Operations \& Production Management, 21 (11), 1433-1451. https://doi.org/10.1108/01443570110407436

Urban, W. (2015). Organizational culture assessment as a means of lean management maturity diagnosis. Journal of Management and Finance, 13(4), 131-139.

Utterback, J. M., \& Abernathy, W. J. (1975). Dynamic Model of Process and Product Innovation. International Journal of Management Science, 3(6), 639-656. https://doi.org/10.1016/0305-0483(75)90068-7

Womack, J. P., Daniel, T. J., \& Daniel, R. (1990). The Machine That Changed the World. Free Press.

Womack, J., \& Jones, D. (1996). Lean Thinking. New York: Simon \& Schuster New York.

\section{Copyrights}

Copyright for this article is retained by the author(s), with first publication rights granted to the journal.

This is an open-access article distributed under the terms and conditions of the Creative Commons Attribution license (http://creativecommons.org/licenses/by/4.0/). 